\title{
Human Resource Management Practice, Knowledge Management Guidance and Enterprise Performance
}

\author{
Liu Junyong \\ Weinan Normal University, Weinan, Shaanxi, 714000
}

Keywords: Human Resource Management Practice, Knowledge Management Guidance, Enterprise Performance, Empirical Research, Structural Equation Model

\begin{abstract}
With the development of the economy and the progress of the society, talent has become an indispensable part of today's society. The level of talents in a country or a region determines the level of economic and technological development of a country to a large extent. We can say that the competition in today's society is the competition of talents. Talent is the core of the development of a country and enterprise, so the most important thing in today's society is the talent. The strength of an enterprise is reflected in the management of talents. If there are only talents but not management, it will not play any role, or even play an opposite role. Therefore, it is equally important to enter the social human resource management. Talents and advanced management concepts and value culture constitute the core competitiveness of enterprises, which determines the performance of enterprises and realizes the sustainable development of enterprises. This paper mainly studies the impact of human resource management practice and knowledge management orientation on enterprise performance. Aiming at these conclusions, we finally summarize how to improve and develop human resource management practices and knowledge management strategies, in order to improve the human resource management discipline and increase business efficiency.
\end{abstract}

\section{Introduction}

With the reform and opening up and the globalization of the economy, people's lives are also changing quietly. More and more countries pay more and more attention to the development of talent. The strategy of "invigorating the country with science and education and developing a country with great power" has fully demonstrated that the country attaches great importance to the development of talent and attaches importance to the practice of human resource management [1-2]. The traditional management model has not adapted to the present situation and the economic development situation, and needs the enterprise innovation management model and the management system. Actively introduce advanced human resources management model, play the role of talent, improve the sustainable development ability of enterprises, and increase social benefits.

\section{Related Concepts}

\subsection{Human resource management}

Human resource management, as its name implies, is the centralized management of talents through a specialized and humanized way. By means of propaganda, recruitment, hunting and employment, human resources concentrate resources and choose suitable jobs. Through a series of pre job training, human resources are gradually adapted to the needs of enterprise positions, creating value for enterprises and meeting the development needs of enterprises [3]. Human resources management also includes follow-up personnel services, personnel benefits and even the operation of personnel leaving the related procedures. Therefore, it can be said that human resource management covers the whole stage of talent entry from enterprise to post and is an indispensable functional department of an enterprise. 


\subsection{Knowledge management}

Knowledge management is the most basic of the enterprise's own culture and values. Whenever a new employee enters a job, it starts with understanding the values and rules and regulations of the enterprise, so that every employee can restrain his behavior through the culture and system of the company. Knowledge management also includes management of post professional knowledge. Through daily and regular business capacity assessment or regular business knowledge exchange and learning, we can enhance professional knowledge reserve and practical operation skills of enterprise talents [4]. The popularity of humanistic knowledge, improve the comprehensive quality of talents; through the integration of information technology and the realization of one plus one is greater than two effect; through the above knowledge management means, advanced and can keep the vitality of the company personnel, constantly adapt to changing internal system and mechanism reform of the external market environment.

\subsection{Enterprise performance}

The enterprise performance, as its name implies, refers to the business benefit and business benefit of this enterprise. The limited period of corporate performance is the performance level linked to the operators in a fixed period of operation. During this fixed period of operation, the number of talents and the strength of talents is the main reference [5]. The performance level of enterprises is reflected in the financial statements, mainly in several corporate financial indicators, including debt paying ability, profitability and capital turnover, liquidity ratio, quick ratio and so on. But these financial indicators are not the only factors that determine the level of business performance. Other non-financial factors will also become the factors that influence the performance of enterprises, such as the number of talents, the quality of talents, the ability of human resource management, etc., which also affect the performance of enterprises.

\section{Human Resource Management under the Background of Knowledge Management}

Under the background of knowledge economy, the competitiveness of enterprises is embodied in the number of resources, the competitiveness of business and the culture of enterprises. The expression of the internal competitiveness of enterprises is reflected in the continuous optimization and innovation management mode within the enterprise, and the core competitiveness of enterprises is reflected through the knowledge resources, management level and core culture management of enterprises.

\subsection{The relationship between human resources and knowledge resources}

Human resources and knowledge resources are the important components and key factors that constitute the core competitiveness of the enterprise. Enterprise human resources, can develop the knowledge resources of the enterprise, the same enterprise, have a strong knowledge of resources, by means of information or advanced management mode, the human resources and information resources to achieve the integration of development, produce one plus one is greater than two effect [6]. By acquiring human resources, enterprises can have knowledge resources at the same time, but acquiring knowledge resources does not necessarily mean that enterprises have human resources. Therefore, only with human resources, can the knowledge resources of the enterprise rely on it, and can play its role [7]. When evaluating enterprise performance, we should not only look at human resources or knowledge resources unilaterally, but combine them to evaluate the whole enterprise's management level and enterprise atmosphere.

\subsection{The interaction between the practice of human resource management and the guidance of knowledge management}

Through knowledge management, enterprises can achieve the purpose of improving the comprehensive quality of talents. Through the integration with information technology, we can achieve the effect of "one plus one more than two". By means of knowledge management, we can maintain the advanced nature and vitality of the talent team and constantly adapt to the changing 
market environment and the reform of internal system and mechanism [8]. At the same time, the practice of human resource management is also good enough to promote the dissemination and communication of enterprises' internal culture, and promote the increase of knowledge reserves of enterprises, which is more conducive to the development of enterprise knowledge management [9]. In a word, the relationship between the practice of human resource management and the guidance of knowledge management is complementary and mutually promoting, and the two are inseparable. Only by dealing with the relationship between the practice of human resource management and the guidance of knowledge management, can the rapid development and sustainable development of the enterprise be realized better.

\subsection{Knowledge management guidance depends on the management of human resources management to realize the value}

The realization of knowledge management requires human resource management to play a role. The knowledge management part should mobilize the human resources management department to organize the personnel to learn when they are propagandizing. We should thoroughly understand the contents of knowledge management, improve the professional knowledge and practical operation level of enterprises, enhance the spirit of solidarity and cooperation among employees, and enhance the cohesion within enterprises [10]. In short, as the first part of this chapter says, enterprises can have knowledge resources at the same time by obtaining human resources. Acquiring knowledge resources does not necessarily mean that enterprises will have human resources. Therefore, only with human resources and knowledge resources, can enterprises play their role. It can be seen that the guidance of enterprise knowledge management needs the practice of human resources of enterprises to play a role, without the knowledge resources of human resources. It is only a set up in the enterprise, a pool of passive water and a wood without root. Knowledge resources can play a role through human resources.

\section{The Influence of Human Resource Management Practice on Enterprise Performance}

\subsection{The influence of employee recruitment on Enterprise Performance}

The impact of recruitment on enterprise performance is reflected in the performance of the enterprise, the recruitment of employees adds vitality to the enterprise, and provides a strong productive force for the enterprise. Delivery of human resources and provide more knowledge resources for enterprises, such as enterprise recruitment, professional knowledge ability of the employees will get more with more professional knowledge resources, makes the enterprise job need to be satisfied, maintain the normal operation of the enterprise [11]. If the enterprise recruitment is more comprehensive staff in all aspects, it will add more comprehensive knowledge resources to the enterprise. These employees are highly adaptable. Later, they can flexibly arrange positions to fill vacancies, and have greater flexibility, which is also conducive to the rational allocation of human resources in enterprises. To sum up, the performance level of the enterprise will be improved.

\subsection{The influence of employee training on Enterprise Performance}

The regular or irregular business training of the employees will improve the professional quality and comprehensive quality of the employees. The knowledge resources obtained by the staff during the training process will be used in the actual work process. The training of employees is beneficial for employees to improve their professional qualities, as well as stimulate their enthusiasm and motivation, and facilitate their orderly operation [12]. Through training assessment, enterprises can comprehensively assess employees with high professional quality, improve the space and opportunities for excellent employees, help outstanding talents to be discovered and inspire their fighting spirit and motivation. Through the promotion mechanism, the reasonable arrangement of Posts has ensured the orderly operation of the enterprise. Improve the performance level of the enterprise and realize the sustainable management of the enterprise. 


\subsection{The impact of rewards and punishment mechanism on Enterprise Performance}

The mechanism of rewards and punishment is an indispensable link in the management of human resources in enterprises. Through the survival of the fittest, the excellent staff should give a good space for promotion. For the employees who do not meet the needs of the post, we should strengthen the training to adapt to the basic needs of the post. For employees who are totally not suited to their positions, they should give humane care, timely adjust staff positions, achieve staff value, and achieve rational allocation of human resources within enterprises, so as to reduce the actual business cost of enterprises. For promotion and salary reward, it can stimulate the working motivation of the employees and invigorate the good atmosphere of the enterprise. Through the incentive and publicity of the enterprise, the personal value of the employee is reflected, and it can also retain the talent, which is of great significance to the enterprise performance.

\section{The Influence of Knowledge Management Orientation on Enterprise Performance}

The knowledge resource is the cornerstone of the enterprise development, and the enterprise only has the rich knowledge resources. In order to realize the value of human resource management practice, the correct guidance of knowledge management is set up. Only knowledge management guidance and human resource management practice at the same time can ensure that the enterprise performance level is steadily increasing. The development of enterprise knowledge management can lead to the correct and leading knowledge of the whole world and the whole world through the combination of information technology. It is integrated with the characteristics of the enterprise to achieve the growth of knowledge resources and the continuous development of the knowledge resources. At the same time, through the management practice of human resources, the creativity of the employees is realized and the creation of knowledge resources is realized. For enterprise knowledge resources to provide growth of fertile soil, promote the process of enterprise modernization, to achieve the improvement of enterprise performance.

\section{Conclusion}

To sum up, the practice of human resource management has a positive effect on knowledge management orientation, and has a positive effect on enterprise performance through knowledge management orientation, that is, knowledge management orientation plays a part in the role of human resource management practice and enterprise performance. Only by relying on excellent talents can not achieve the goal of improving enterprise performance. Knowledge management can be used as a medium to link human resources to enterprise performance. In the new situation of economic development, in the process of doing a good job of knowledge resources innovation, enterprises should constantly strengthen the management of human resources. The personnel of a company should have higher information capacity, lifelong learning ability and certain information capacity. We should establish good personal morality and professional ethics, and do things illegal, and strengthen our own constraints. At the same time, we should keep pace with the times, improve their professional quality and business ability, make suggestions for the enterprise to reduce the cost and increase the efficiency, and do all the professional talents.

\section{References}

[1] Chen J, Li W. The Relationship between Flexible Human Resource Management and Enterprise Innovation Performance: A Study from Organizational Learning Capability Perspective[M]// Information and Knowledge Management in Complex Systems. Springer International Publishing, 2015:1-49.

[2] Zimmermann O. Architectural Knowledge Management: Decision Guidance in Service-Oriented Architecture Design[J]. Software Engineering Institute, 2015.

[3] Sánchez A A, Morales A M. The mediating effect of strategic human resource practices on 
knowledge management and firm performance[J]. Revista Europea De Dirección Y Economía De La Empresa, 2015, 24(3):138-148.

[4] Guo X, Li Z, Luo Q, et al. Research on Supply Side Optimization of Human Resources in National-owned Knowledge-based Enterprises_-A Case Study of Electric Power Enterprise[J]. Industrial Economy Review, 2017.

[5] Yang Z Y. Employment Guidance for Undergraduates Major in Human Resource Management Based on Competence[J]. Journal of Hubei Correspondence University, 2017.

[6] Li H E. Practice and Thought of Strategic Human Resource Management under Oil Company System and Mechanism[J]. Journal of Jianghan Petroleum University of Staff \& Workers, 2016.

[7] Kuimet K, Järvis M, Virovere A, et al. Linking Human Resource Management and Knowledge Management via Commitment to Safety[M]// The Implementation of management science /. North-Holland Pub. Co. 2015:17-25.

[8] Lei Z, Shi Z. Research on Process Model of Organization of Human Resource Management Based on the System Engineering Methodology[J]. Journal of Tianjin University, 2017.

[9] Silva R S G D. Guidelines to innovate organizations by knowledge management via communities of practice[C]// XXXIV National Meeting of Production Engineering. 2016.

[10] Gonzalez R V D, Martins M F. Knowledge management and organizational development[J]. 2014.

[11] Zhang Y, Tian Z. Analysis of Influence of Profits on Employees and Enterprises based on the Reform of the Concept of Human Resource Management of SMEs[C]// International Conference on Education, Management and Social Science. 2014.

[12] Wang S Y, Hsu S C, Lin T C, et al. Promoting uncommon knowledge use within is department: Human resource management perspective[J]. 2014. 